\title{
Interactions between RNase $P$ protein subunits in Archaea
}

\author{
THOMAS A. HALL ${ }^{1}$ and JAMES W. BROWN $\mathrm{W}^{2,3}$ \\ ${ }^{1}$ Ibis Therapeutics, 2292 Faraday Ave., Carlsbad, CA 92008, USA \\ 2 Department of Microbiology, North Carolina State University, Raleigh, NC 27695, USA \\ ${ }^{3}$ Corresponding author(james_brown@ncsu.edu)
}

Received October 6, 2003; accepted December 22, 2003; published online February 6, 2004

\begin{abstract}
Summary A yeast two-hybrid system was used to identify protein-protein interactions between the ribonuclease $\mathrm{P}$ (RNase P) protein subunits Mth11p, Mth687p, Mth688p and Mth1618p from the archaeon Methanothermobacter thermoautotrophicus. Clear interactions between Mth688p and Mth687p, and between Mth1618p and Mth11p, were confirmed by HIS3 and LacZ reporter expression. Weaker interactions of Mth687p and Mth688p with Mth11p, and Mth11p with itself, are also suggested. These interactions resemble, and confirm, those previously seen among the homologs of these proteins in the more complex yeast RNase $\mathrm{P}$ holoenzyme.
\end{abstract}

Keywords: archaebacteria, MTH11, MTH1618, MTH687, MTH688, ribonuclease $P$.

\section{Introduction}

Ribonuclease $\mathrm{P}$ (RNase $\mathrm{P}$ ) is a ubiquitous RNA processing enzyme required in the maturation of pre-tRNAs as a prerequisite to protein synthesis (for review, see Pace and Brown 1995, Frank and Pace 1998, Schön 1999). Ribonuclease P removes the $5^{\prime}$ leader sequence from tRNA precursors in a magnesium-dependent endonucleolytic reaction characterized by a single-stranded cleavage just $5^{\prime}$ of a double-stranded helix, resulting in $5^{\prime}$ phosphate and $3^{\prime}$ hydroxyl groups. Ribonuclease $\mathrm{P}$ activity has been found in all cells and in intracellular organelles examined containing translational machinery. In all cases in which the composition of RNase P is known, it comprises a single RNA and proteins that vary by phylogenetic domain. In bacteria and some archaea, RNase P RNA is catalytic in vitro in the absence of protein (Guerrier-Takada et al. 1983, Pannucci et al 1999). There is evidence that the RNA is the catalytic subunit in other RNase P systems as well (with the possible exception of that of plant chloroplasts (Thomas et al. 2000)) although the RNA component of eukaryotic nuclear RNase $P$ has not been shown to be enzymatic in the absence of RNase P protein subunits (Lee and Engelke 1989, Lee et al. 1991, Thomas et al. 2000).

In all bacteria examined, RNase P contains an RNA of $\sim 95-140 \mathrm{kDa}(300-450 \mathrm{nt})$ and a single small protein of 13-17 $\mathrm{kDa}$. In the eukaryotic nucleus, RNase $\mathrm{P}$ is more complex, comprising at least nine protein subunits in Saccharomyces cerevisiae (Chamberlain et al. 1998) and at least 10 proteins in humans (Lygerou et al. 1996, Eder et al. 1997, Jarrous et al. 1998, 1999, 2001, 2002, Jiang and Altman 2001). Bacterial, eukaryotic and archaeal RNase P RNAs all share a common set of elements thought to contribute to a universally conserved catalytic core (Chen and Pace 1997). Outside this core structure, bacterial and archaeal RNase P RNAs are similar to one another and very different from eukaryotic nuclear RNAs (Pitulle et al. 1998, Frank et al. 2000, Harris et al. 2001). Despite the similarity of the archaeal and bacterial RNase P RNAs, archaeal RNase P enzymes contain at least four protein subunits that are homologous to subunits of eukaryotic nuclear RNase P rather than those of bacteria, and archaeal genomes do not contain an open reading frame encoding an obvious homolog of any bacterial RNase P protein (Hall and Brown 2002).

Although eukaryotic and archaeal RNase P protein subunits have been identified, the organization of the subunits in the holoenzyme complex is unknown in both cases. Even in bacteria, the architecture of the RNase P holoenzyme has not been determined, although the structures of the Bacillus subtilis, Staphylococcus aureus and Thermotoga maritima RNase P protein subunits have been solved (Stams et al. 1998, Spitzfaden et al. 2000, Kazantsev et al. 2003) and predictive models have been produced for the three-dimensional structure of the bacterial RNA subunit (Chen et al. 1998, Massire et al. 1998) and the holoenzyme (Tsai et al. 2003). Bacterial RNase $\mathrm{P}$ holoenzyme activity is easily reconstituted in vitro by mixing protein and RNA subunits together (Baer et al. 1989, Kirsebom and Vioque 1995). The reconstitution of functional archaeal RNase P holoenzymes from the RNA and four known RNase P proteins has recently been published (Boomershine et al. 2003, Kouzuma et al. 2003). A preliminary account of the reconstitution of RNase P activity from the human homologs of these four proteins (out of the collection of 10 known human RNase P-associated proteins) and RNase P RNA has recently been reported (Mann et al. 2003). Yeast two- and three-hybrid analyses have suggested protein-protein and RNA-protein interactions in human and yeast RNase P holoenzymes (Jiang and Altman 2001, Jiang et al. 2001, Houser- 
Scott et al. 2002), but the human and yeast results largely disagree even between homologous subunits.

In this investigation, we analyzed potential protein-protein interactions between four identified subunits of RNase P from the archaeon Methanothermobacter thermoautotrophicus: Mth11p, Mth687p, Mth688p and Mth1618p (Hall and Brown 2002) by yeast two-hybrid assays.

\section{Materials and methods}

\section{Construction of two-hybrid expression plasmids}

The MTH11, MTH687, MTH688 and MTH1618 open reading frames were amplified by polymerase chain reaction (PCR) from $M$. thermoautotrophicus genomic DNA with the primers shown in Table 1. The PCR products were each cloned into the SmaI and SalI sites of the pLexA (pBTM116) "bait" plasmid (Bartel et al. 1993) as amino-terminal in-frame fusions to the LexA DNA binding domain. The same PCR products were cloned into the SmaI and XhoI sites of the pACT2 "target" plasmid (Clontech, Palo Alto, CA) as amino-terminal in-frame fusions to the GAL4 transcriptional activator domain.

Yeast two-hybrid analysis of all combinations of MTH11, MTH687, MTH688 and MTH1618

Double transformations of yeast strain L40 (Hollenberg et al. 1995) were performed as described for lithium acetate-aided transformation (Soni et al. 1993) with the following modifications: 0.5 to $1.25 \mu \mathrm{g}$ of each plasmid was used with $25 \mu \mathrm{g}$ of sheared and boiled salmon sperm DNA as a carrier, and heat shock was performed at $42{ }^{\circ} \mathrm{C}$ for $20 \mathrm{~min}$. The genotype of the L40 yeast strain is Mata his3D200 trp-1901 leu2-3,112 ade LYS::(lexAop)4-HIS3 URA3::(lexAop)8-lacZ GAL4 (36). The pACT2 plasmid contains a LEU2 marker and pLexA contains a TRP1 marker. All combinations of MTH11, MTH687, MTH688 and MTH1618 in pLexA and pACT2 were tested. Methanothermobacter thermoautotrophicus genes in pACT2 cotransformed with empty pLex, M. thermoautotrophicus genes in pLexA cotransformed with empty pACT2, and empty pLexA cotransformed with empty pACT2 served as negative controls. A positive control was provided by double-transfor- mation with murine Ras in pLexA and murine Rip51 in pVP16. Double-transformants were plated directly to synthetic medium (SD) lacking Trp, Ura, Leu and Lys, with 2\% glucose (SD -WULK medium) and grown at $30^{\circ} \mathrm{C}$ until colonies appeared.

Two colonies from each of the transformation plates were screened for growth in the absence of histidine. Each colony was suspended in $20 \mu \mathrm{l}$ of $\mathrm{ddH}_{2} \mathrm{O}$ and $3 \mu \mathrm{l}$ was streaked onto SD -WULK and SD -WULK lacking His (SD -WULKH) and containing $0,1,5$, or $10 \mathrm{mM}$ 3-amino-1,2,4-triazole (3-AT, Sigma, St. Louis, MO) to help reduce the effects of weak HIS3 expression. This entire procedure was performed twice, starting with a separate starter culture of L40 yeast and separate preparations of all plasmid constructs, with the exclusion of the $1 \mathrm{mM}$ 3-AT plates. Plates were incubated at $30^{\circ} \mathrm{C}$ for 3 to 5 days. Results obtained for the two runs were similar. To test for $\beta$-galactosidase expression, two colonies of each test and one colony from each control were streaked onto plates of SD lacking Trp, Ura and Leu (SD -WUL) with X-gal (see below) and incubated at $30^{\circ} \mathrm{C}$.

Confirmation of positive interactions on $-H i s+20 \mathrm{mM} 3-\mathrm{AT}$ and $X$-gal plates

Three colonies each of pACT2-MTH1618/pLexA-MTH11, pACT2-MTH11/pLexA-MTH1618, pACT2-MTH688/pLexA-MTH687 and pACT2-MTH687/pLexA-MTH688 that grew on SD -WULKH + $10 \mathrm{mM} 3$-AT were suspended in $50 \mu \mathrm{l}$ $\mathrm{ddH}_{2} \mathrm{O}$ and $4 \mu \mathrm{l}$ were streaked onto SD -WULK plates and incubated at $30{ }^{\circ} \mathrm{C}$ to grow single colonies in the absence of strong selection for HIS3 expression. The same was done with three colonies each from pACT2/pLexA-MTH11, pACT2-MTH11/pLexA, pACT2/pLexA-MTH1618, pACT2MTH1618/pLexA, pACT2/pLexA-MTH687, pACT2-MTH687/pLexA, pACT2/pLexA-MTH688 and pACT2-MTH688/ pLexA, which had grown on SD -WULK. A single colony was dissolved in $100 \mu \mathrm{l}$ of $\mathrm{ddH}_{2} 0$ and $4 \mu \mathrm{l}$ of twofold serial dilutions were spotted onto SD -WULK, SD -WULKH + 0, 5, 10 and $20 \mathrm{mM} 3-\mathrm{AT}$, and SD -WUL X-gal (see below). Plates were incubated at $30{ }^{\circ} \mathrm{C}$ and photographed when growth reached a reasonable size.

Table 1. Primers used to amplify M. thermoauthotrophicus genomic DNA.

\begin{tabular}{|c|c|c|}
\hline Gene & Primer name & Sequence \\
\hline МTH11 & $\begin{array}{l}\text { YHS115'SmaI } \\
\text { YMTH113'XhoI }\end{array}$ & 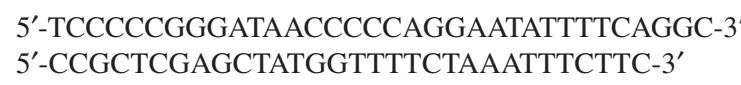 \\
\hline МТн687 & $\begin{array}{l}\text { YHS6875'SmaI } \\
\text { YMTH6873'XhoI }\end{array}$ & 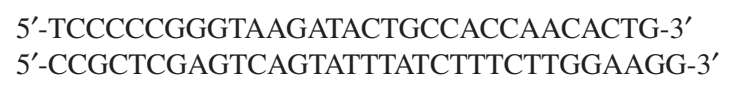 \\
\hline МTH688 & $\begin{array}{l}\text { YHS6885'SmaI } \\
\text { MTH6883'XhoI }\end{array}$ & $\begin{array}{l}\text { 5'-TCCCCCGGGTATTCCCCAAAGGATTCTG-3' } \\
\text { 5'-CCGCTCGAGTTAACTCTCAGGGAGGAGCC-3' }\end{array}$ \\
\hline МTH1618 & $\begin{array}{l}\text { YHS16185'EcoRV } \\
\text { YMTH16183'XhoI }\end{array}$ & 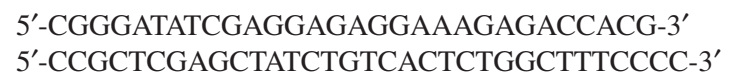 \\
\hline
\end{tabular}


A.

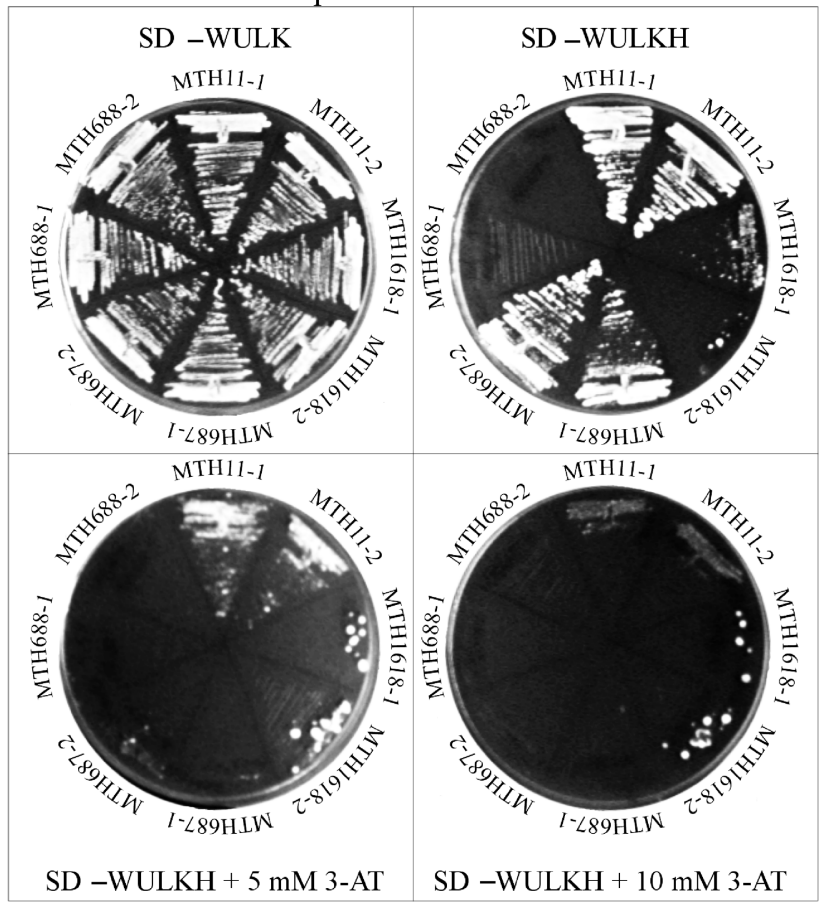

B.

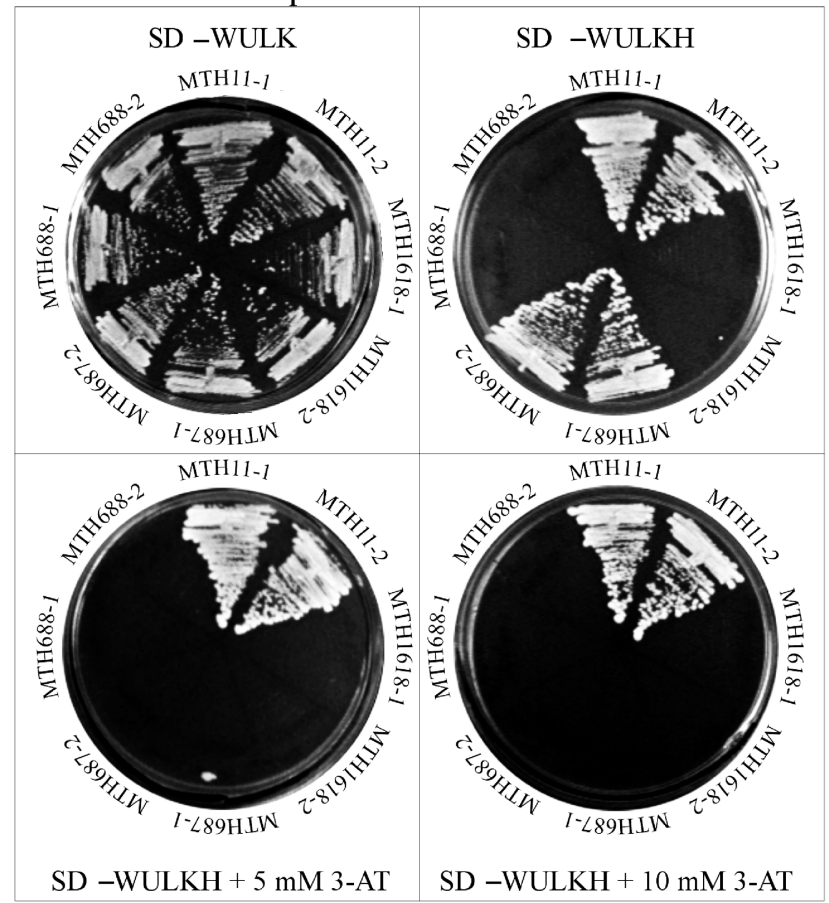

C.

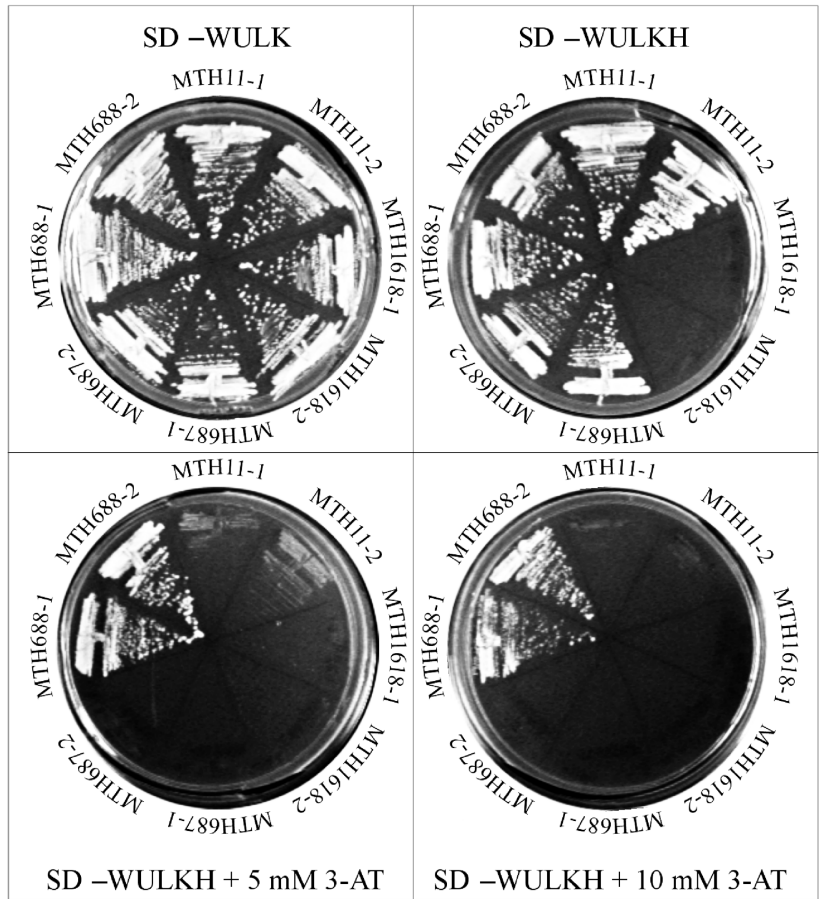

D.

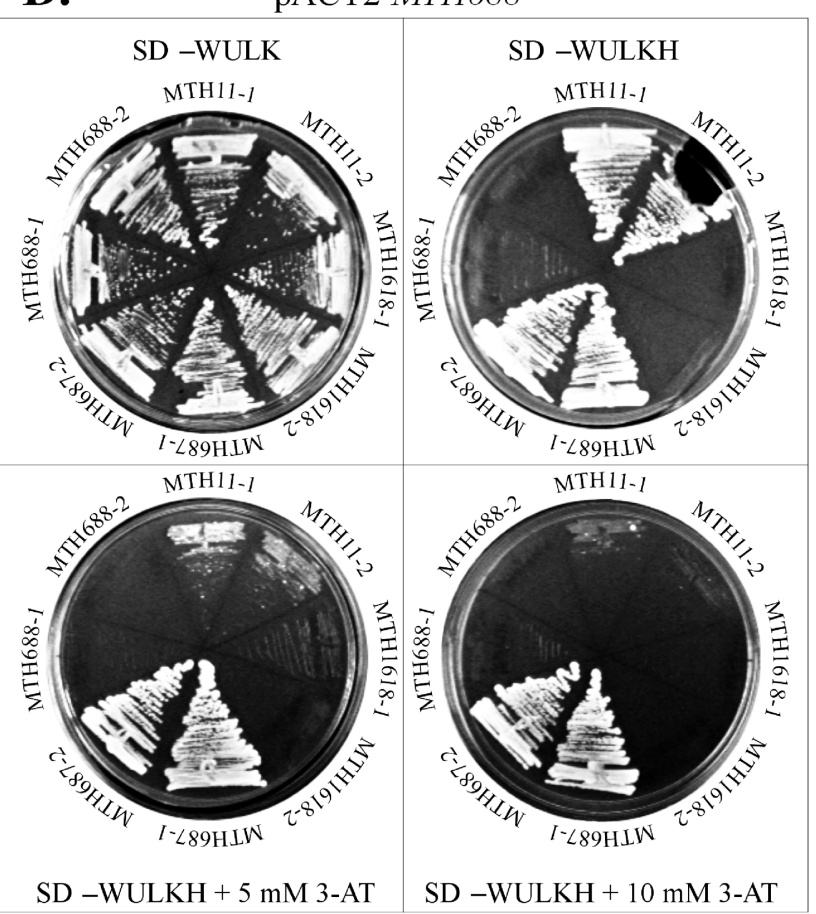

Figure 1. Selection of double transformants for HIS3 expression. Yeast cells transformed with all combinations of MTH11, MTH687, MTH688 and MTH1618 in pACT2 and pLexA two-hybrid vectors were streaked onto synthetic medium (SD -WULK) lacking histidine (H) and containing up to $10 \mathrm{mM}$ 3-AT (3-amino-1,2,4-triazole), a histidine pathway inhibitor. The growth of colonies at $10 \mathrm{mM} 3$-AT suggests a protein-protein interaction between the protein fused to the LexA binding domain (encoded by pLexA) and the protein fused to the GAL4 transcriptional activator domain (encoded by pACT2). Plates are organized in groups according to the gene fused in the pACT2 plasmid as indicated above each group. The first plate in each group contains histidine and is a control to verify even streaking of the plates. The next three plates in each group lack histidine and contain 0, 5 and $10 \mathrm{mM} 3-\mathrm{AT}$, respectively. Each selection was done in duplicate. 


\section{Yeast X-gal medium}

Synthetic X-gal plates contained $0.6 \%$ yeast nitrogen base, $2 \%$ agar, $2 \%$ glucose, $20 \mu \mathrm{g} \mathrm{ml}^{-1}$ adenine sulfate, $20 \mu \mathrm{g} \mathrm{m} \mathrm{m}^{-1}$ arginine, $20 \mu \mathrm{g} \mathrm{ml}^{-1}$ methionine, $30 \mu \mathrm{g} \mathrm{ml}^{-1}$ isoleucine, $30 \mu \mathrm{g}$ $\mathrm{ml}^{-1}$ lysine, $50 \mu \mathrm{g} \mathrm{ml}^{-1}$ phenylalanine, $100 \mu \mathrm{g} \mathrm{ml}^{-1}$ glutamic acid, $100 \mu \mathrm{g} \mathrm{ml}^{-1}$ aspartic acid, $150 \mu \mathrm{g} \mathrm{ml}^{-1}$ valine, $200 \mu \mathrm{g}$ $\mathrm{ml}^{-1}$ threonine, $400 \mu \mathrm{g} \mathrm{ml}^{-1}$ serine, $100 \mathrm{mM} \mathrm{KH}_{2} \mathrm{PO}_{4}, 0.2 \%$ $\left(\mathrm{NH}_{4}\right)_{2} \mathrm{SO}_{4}, 0.42 \% \mathrm{KOH}, 200 \mu \mathrm{g} \mathrm{ml}{ }^{-1} \mathrm{MgSO}_{4} \cdot 7 \mathrm{H}_{2} \mathrm{O}, 800 \mathrm{ng}$ $\mathrm{ml}^{-1} \mathrm{FeCl}_{3} \cdot 6 \mathrm{H}_{2} \mathrm{O}, 400 \mathrm{ng} \mathrm{ml}^{-1}$ vitamin $\mathrm{B} 1,20 \mathrm{ng} \mathrm{ml}^{-1}$ biotin, $400 \mathrm{ng} \mathrm{ml}^{-1}$ pantothenic acid, $2 \mu \mathrm{g} \mathrm{ml}^{-1}$ inositol, $400 \mathrm{ng} \mathrm{ml}^{-1}$
A.

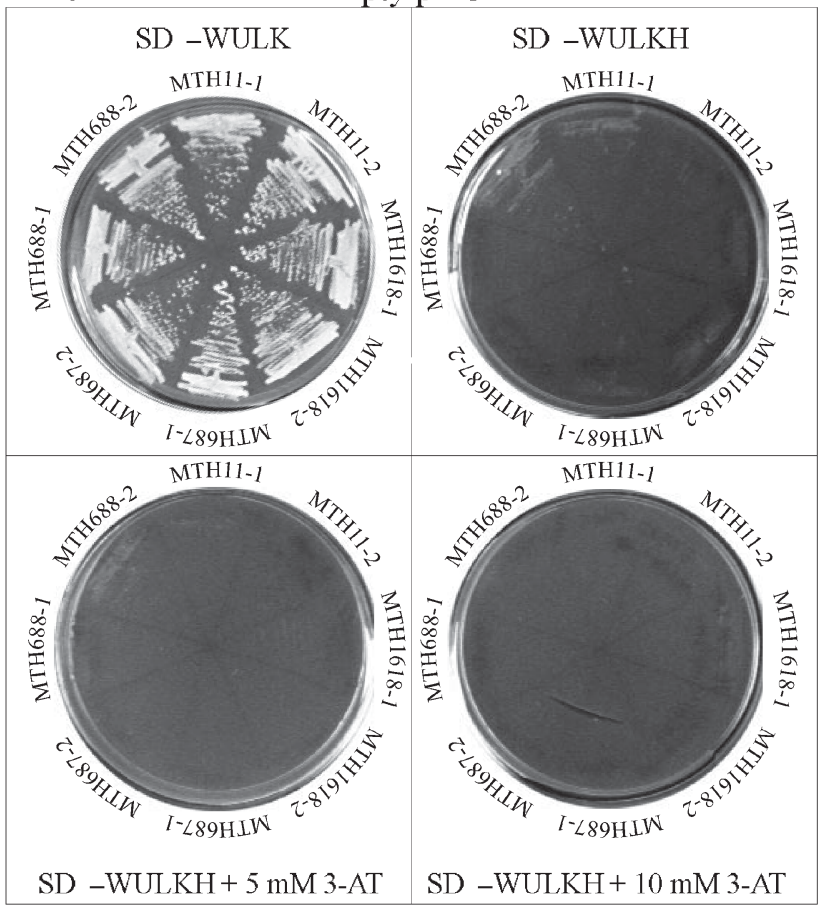

B.

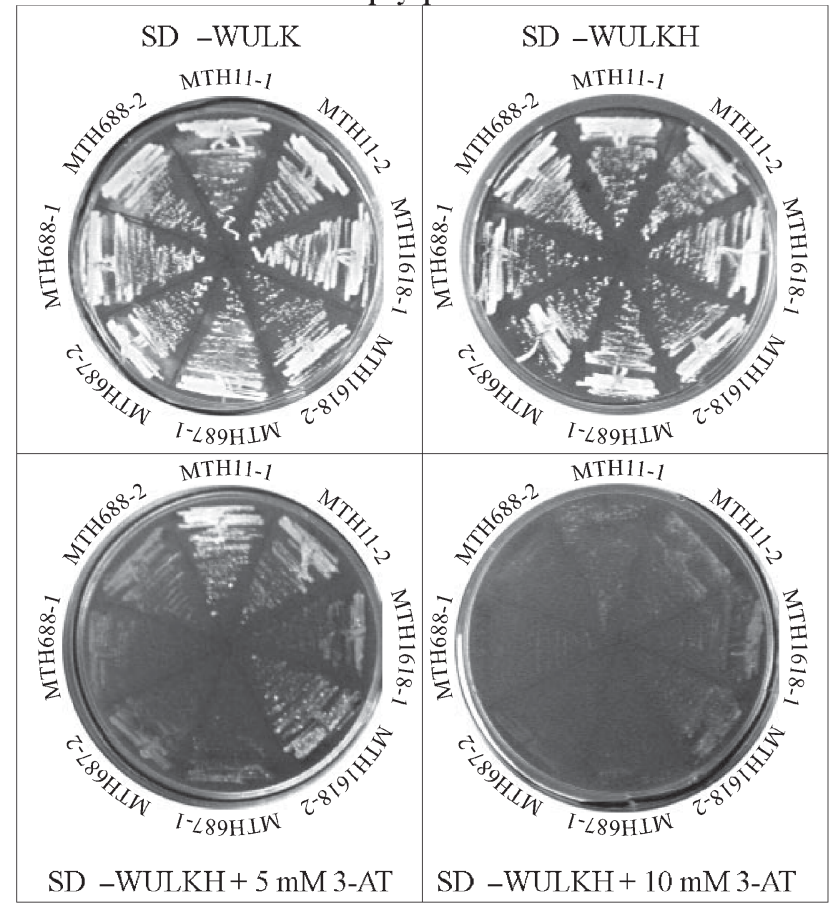

C. Empty vectors (-) and pVP16-Rip51/pLexA-Ras (+)

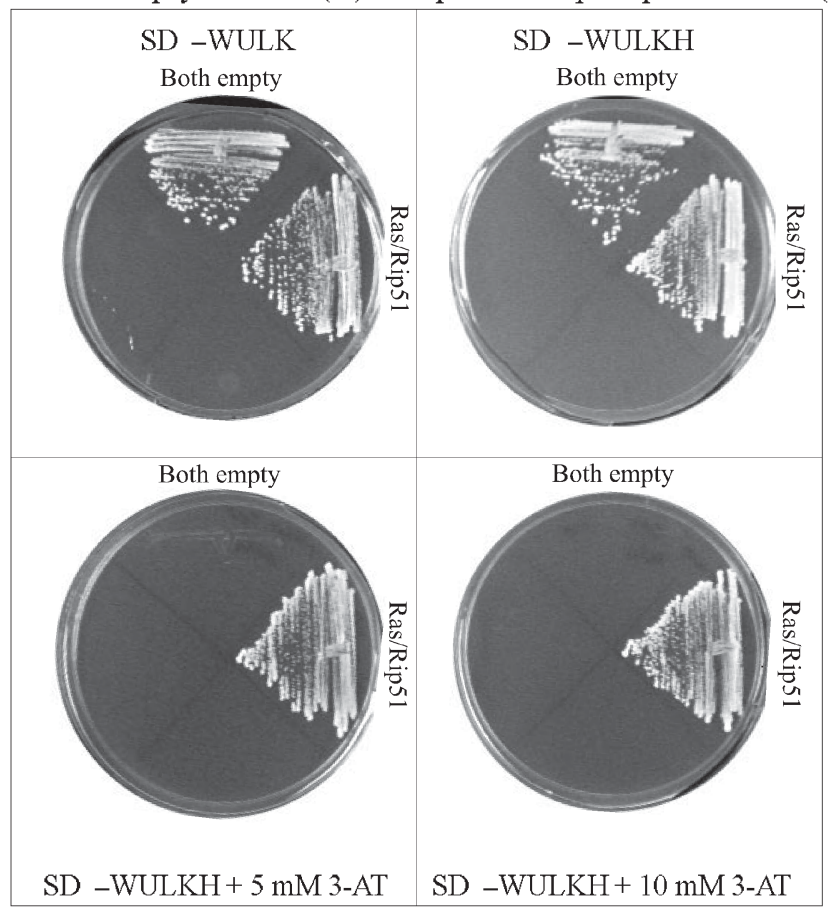

Figure 2. Controls for the results of the selection of double transformants for HIS3 expression shown in Figure 1. Yeast cells transformed with (A) MTH11, MTH687, MTH688 and MTH1618 in pLexA and an empty pACT2 vector, (B) MTH11, MTH687, MTH688 and MTH1618 in pACT2 and an empty pLexA vector, and (C) empty pACT2 and empty pLexA, or vP16-Rip51/pLexA-Ras (a positive control) were streaked onto synthetic medium (SD -WULK) lacking histidine $(\mathrm{H})$ and containing up to $10 \mathrm{mM}$ 3-AT (3-amino-1,2,4-triazole), a histidine pathway inhibitor. Organization of the plates is the same as shown in Figure 1. 
pyridoxine, and $80 \mu \mathrm{g} \mathrm{ml} \mathrm{m}^{-1} \mathrm{X}$-gal (5-bromo-4-chloro-3-indolyl- $\beta$-D-galactoside).

\section{Results}

Growth on defined medium, without histidine and with up to $10 \mathrm{mM} 3-\mathrm{AT}$, was clearly supported in cells transformed with pACT2-MTH687/pLexA-MTH688 or with pACT2-MTH688/ pLexA-MTH687 (Figures 1C and 1D), suggesting that Mth687p and Mth688p interact in vivo. Growth of cells containing pACT2-MTH1618/pLexA-MTH11 was also supported well up to $10 \mathrm{mM} 3$-AT (Figure 1B). Individual colonies of double transformants of pACT2-MTH11/pLexA-MTH1618 grew well in the presence of the highest concentration of 3-AT inhibitor (Figure 1A), but in every case tested, only scattered colonies grew. This growth pattern differed from both controls (Figure 2) and the other experiments with $10 \mathrm{mM} 3$-AT, where growth tended to be generally inhibited, and weak HIS3 induction resulted in faint, diffuse growth (see Figure 2B). A small
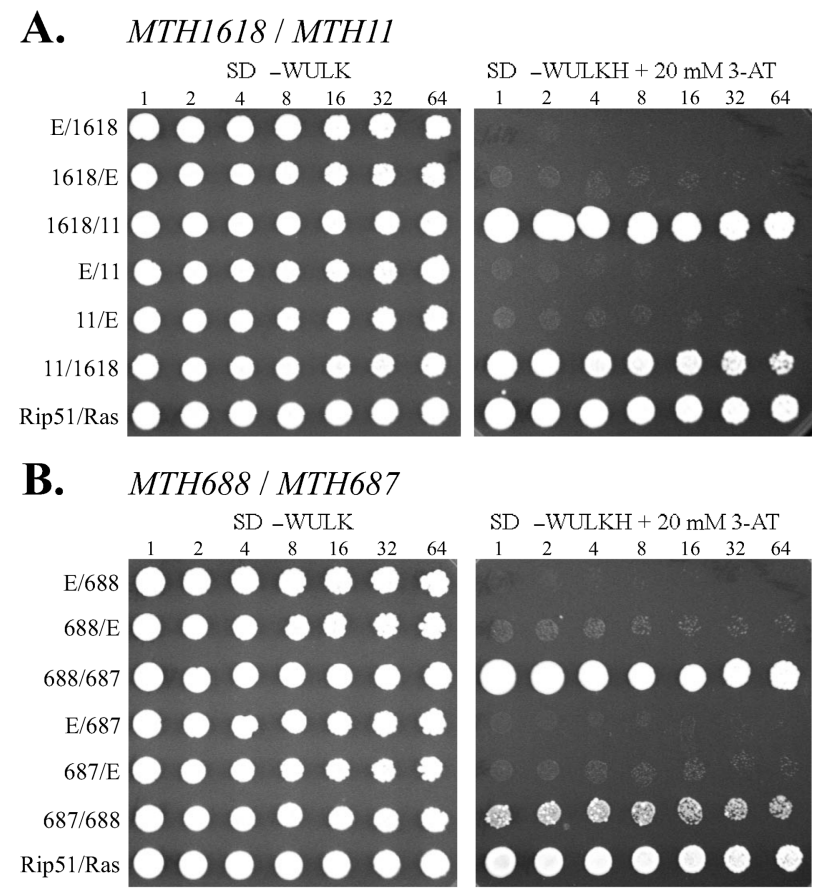

Figure 3. Confirmation of protein-protein interactions at $20 \mathrm{mM} 3-\mathrm{AT}$ (3-amino-1,2,4-triazole). Yeast colonies transformed with the indicated constructs were suspended in $50 \mu \mathrm{ddH}_{2} \mathrm{O}$ and $4 \mu \mathrm{l}$ of the dilution was spotted onto synthetic medium (SD -WULK) with or without histidine $(\mathrm{H})$ and containing up to $20 \mathrm{mM} 3$-AT. Shown above are synthetic medium with histidine (left, a control for yeast viability) and medium without histidine and containing $20 \mathrm{mM} 3$-AT (right). The labels on the left indicate the constructs transformed into each representative. The gene name on the left of the slash refers to the gene in pACT2. The gene name on the right of the slash indicates the gene in pLexA. The letter ' $E$ ' indicates the empty vector. In the positive control, Rip51/Ras, Rip51 is in the pVP16 vector. (A) Growth on $20 \mathrm{mM}$ 3-AT suggests an in vivo interaction between Mth1618p and Mth11p. (B) Growth on $20 \mathrm{mM}$ 3-AT suggests an in vivo interaction between Mth688p and Mth687p. amount of growth was evident at $10 \mathrm{mM}$ 3-AT, where pLexA-MTH11 was present with any of MTH11, MTH687, MTH688 or MTH1618 in pACT2 (Figure 1), but not with empty pACT2 (Figure 2A). However, when streaked on X-gal plates, weak LacZ expression was evident only in pACT2MTH688/pLexA-MTH11 (not shown), suggesting that HIS3 expression could be weakly induced by the Mth11p itself bound to a LexA promoter binding peptide. The Mth687p by

A.
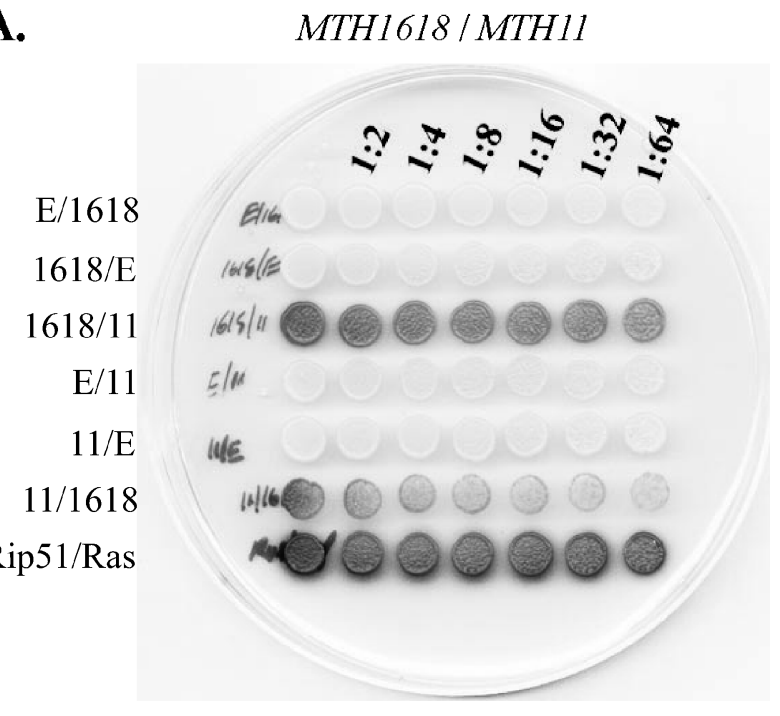

B. MTH688 / MTH687

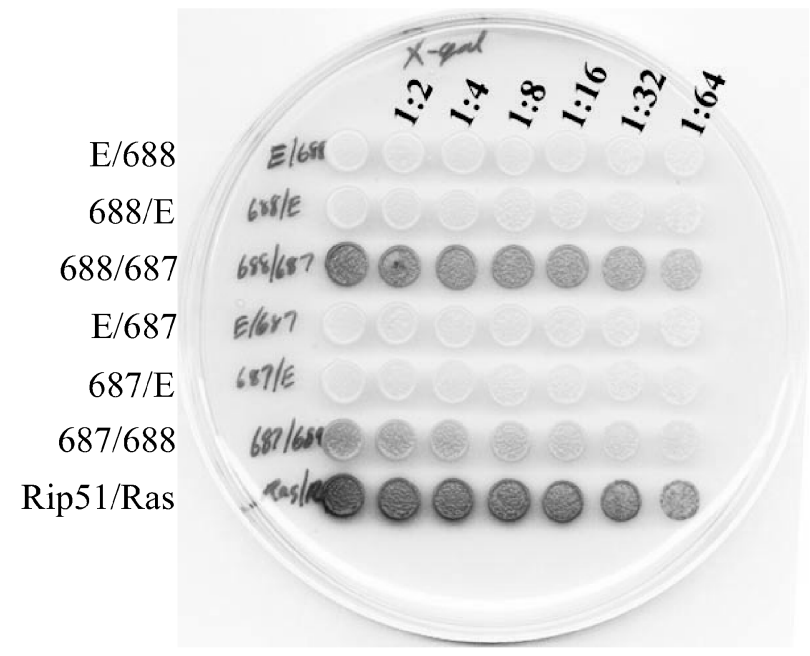

Figure 4. Confirmation of protein-protein interactions on X-gal medium. Yeast colonies transformed with the indicated constructs were suspended in $50 \mu \mathrm{lddH_{2 }} \mathrm{O}$ and $4 \mu \mathrm{l}$ of the dilution was spotted onto synthetic medium containing $80 \mathrm{mg} \mathrm{ml}^{-1} \mathrm{X}$-gal (see Materials and methods). The labels on the left indicate the constructs transformed into each representative. The gene name on the left of the slash refers to the gene in pACT2. The gene name on the right indicates the gene in pLexA. The letter ' $E$ ' indicates the empty vector. In the positive control, Rip51/Ras, Rip51 is in the pVP16 vector. (A) Expression of $\beta$-galactosidase suggests an in vivo interaction between Mth1618p and Mth11p. (B) Expression of $\beta$-galactosidase suggests an in vivo interaction between Mth688p and Mth687p. 
itself appeared able to induce weak LacZ expression (not shown, slightly evident in Figure 4B), but did not support growth on $10 \mathrm{mM} 3$-AT in any combination other than pACT2-MTH688, where induction of both HIS3 and LacZ was strong (Figures 1, 2, 3B and 4B).

When dilutions of colonies containing pACT2-MTH688/ pLexA-MTH687, pACT2-MTH687/pLexA-MTH688, pACT2-MTH1618/pLexA-MTH11 or pACT2-MTH11/pLexAMTH1618 were spotted on defined medium without histidine and containing up to $20 \mathrm{mM} 3$-AT (the highest 3-AT concentration tested), colonies grew within 2 to 4 days, whereas cells containing the open reading frames in either vector in combination with the other empty vector did not grow at this inhibitor concentration (Figure 3). LacZ was clearly induced compared with controls for these combinations as well (Figure 4). The interactions did not appear to be of the same strength in both orientations of pACT2/pLexA. The pACT2MTH688/pLexA-MTH687 interaction appeared to be stronger than the pACT2-MTH687/pLexA-MTH688 interaction (Figures $3 \mathrm{~B}$ and 4B). Likewise, the pACT2-MTH1618/pLexAMTH11 interaction was stronger than the pACT2-MTH11/ pLexA-MTH1618 interaction (Figures 3A and 4A).

\section{Discussion}

Despite a wealth of investigation and detailed information about RNase P from all three domains of life, much of the nature of this ubiquitous enzyme remains elusive. Even in bacteria, where RNase P is best characterized, the overall architecture of the enzyme remains unknown. It also remains unclear whether the biologically relevant form of the enzyme is a monomer or dimer (Fang et al. 2001). Only recently has the subunit composition of eukaryotic nuclear RNase P been established, and this is relatively complete only in yeast (Chamberlain et al. 1998) and humans (Lygerou et al. 1996, Eder et al. 1997, Jarrous et al. 1998, 1999, 2001, 2002, Jiang and Altman 2001). No archaeal RNase P has yet been purified to homogeneity, but four RNase P protein subunits have been identified in $M$. thermoautotrophicus by their copurification with enzyme activity, and the ability of antigen-purified antibodies against each recombinant protein to immunoprecipitate RNase P activity (Hall and Brown 2002). The close resemblance of RNase P RNA secondary structure in archaea to that in bacteria, along with the presence of multiple protein subunits that are homologous to their eukaryotic nuclear counterparts, suggest that archaeal RNase $\mathrm{P}$ represents a primitive view of the subunit composition of RNase $\mathrm{P}$ in the common ancestor of the Archaea and Eukarya.

A recent two-hybrid screen has suggested the in vivo interaction of human nuclear RNase P protein subunits Rpp30 and Rpp14 (Jiang and Altman 2001). Human Rpp14 and yeast Pop5p are homologs and are grouped together with Mth687p and its archaeal homologs into a single COG ("clusters of orthologous groups") family (Koonin et al. 2001). Mth688p is the apparent archaeal homolog of human Rpp30 and yeast Rpp1p, and interacts with Mth687p in our yeast two-hybrid system in both orientations of "bait and target." Furthermore, the corresponding interaction was also seen using the identical vector system and reporter strain used here with yeast Rpp1p in pACT2 and Pop5p in pLexA (Houser-Scott et al. 2002).

Our data suggest an interaction between Mth1618p and Mth11p. The corresponding proteins from $S$. cerevisiae nuclear RNase P, Rpr2p and Pop4p, respectively, and from humans, Rpp21p and Rpp29p, were also observed to interact in two-hybrid systems, although in the case of the yeast proteins the interaction was seen only with Pop4p in the pACT2 plasmid and Rpr2p in the pLexA plasmid (Jiang and Altman 2001, Houser-Scott et al. 2002). In contrast, in our study, the stronger interaction occurred between Mth1618p (similar to Rpr2p) in the pACT2 plasmid and Mth11p (similar to the C-terminus of Pop4p) in the pLexA plasmid. When the proteins were placed in the reverse orientation, the interaction appeared weaker. When grown on $10 \mathrm{mM} 3$-AT, only a few colonies grew, but they grew well (see Figure 1A). This phenomenon was observed in both independent tests using new competent yeast cells and separate plasmid preparations. When colonies that grew on $10 \mathrm{mM} 3$-AT were regrown and spotted on X-gal, they tested positive for $\beta$-galactosidase (Fig-

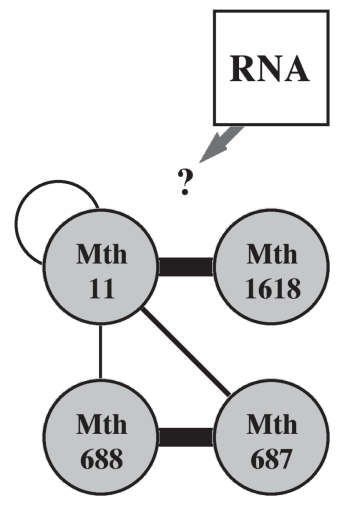

M. thermoautotrophicus

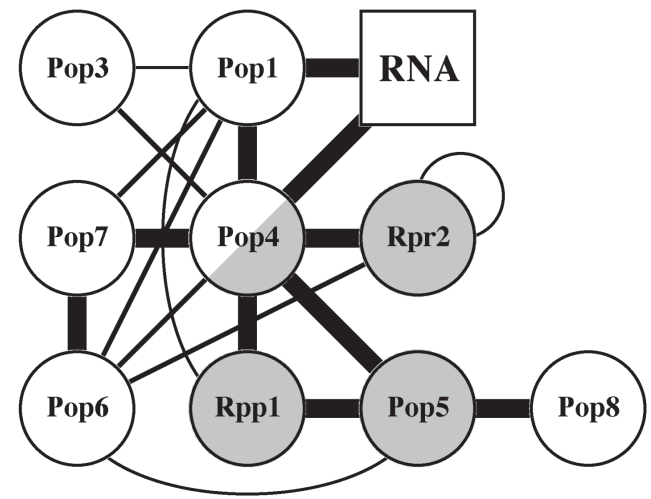

S. cerevisiae
Figure 5. Comparison of known subunit interactions in archaeal and yeast RNase P. Known interactions between subunits of M. thermoautotrophicus (left) and $S$. cerevisiae (right) RNase $\mathrm{P}$ holoenzymes according to the data in Figure 1 and Houser-Scott et al. 2002, respectively. Strong interactions are indicated with heavy lines, weak interactions with thin lines. Homologous proteins in these two systems are shaded grey and are shown in the same relative orientation. The yeast Pop4 protein is shaded half grey to indicate that the N-terminal portion of this protein has no homolog in the smaller Mth11 protein. 
ure 4A). However, when 32 random colonies of pACT2MTH11/pLexA-MTH1618 transformants were streaked onto $\mathrm{X}$-gal plates, only 10 of the colonies appeared to be $\beta$-galactosidase positive (not shown).

Several other weaker interactions have been observed in the yeast nuclear system, including interactions between Pop4p/ Pop5p, Pop4p/Rpp1p and Rpr2p with itself (Houser-Scott et al. 2002). We detected weak potential interactions homologous to those of Pop4p/Pop5p (Mth11p/Mth687p) and Pop4p/Rpp1p (Mth11p/Mth688p), but did not observe the interaction homologous to Rpr2p (Mth1618p) with itself. Instead, we observed a weak potential interaction between Mth11p (Pop4p) and itself (Figure 1), although we consider all of these weaker interactions tentative in contrast to the clear interactions between Mth688p/Mth687p and Mth1618p/ Mth11p. In the yeast system, Pop4p was also seen to interact with many of the other RNase P subunits (Houser-Scott et al. 2002). However, Mth11p corresponds to the carboxyl-terminal half of Pop4p only (Hall and Brown 2002), and protein-encoding sequences homologous to the amino-terminal extension of Pop $4 p$ have not been identified in any archaeal genome. We also tested every combination of $M$. thermoautotrophicus open reading frame constructs in both pACT2 and pLexA in cotransformations with each of the nine S. cerevisiae RNase P subunits in both plasmids, but no evidence for intracellular cross-interactions between any of these heterologous proteins was observed (data not shown). Twohybrid analysis of the human RNase $\mathrm{P}$ proteins suggests a plethora of weak potential interactions, including Rpp29p (homologous to Mth11p and Pop4p) with Rpp30p (homologous to Mth688p), but not Rpp29p with itself (Jiang and Altman 2001). Interactions of hPop5p (homologous to Mth687p and Pop5p) have not been tested. Interactions identified in the human enzyme between Rpp30p (homologous to Mth688p and Rpp1p) and Rpp21p (homologous to Mth1618p and Rpr2p), and Rpp30p with itself, were not seen in our analysis of the archaeal proteins, nor were they reported in the analysis of the yeast proteins (Houser-Scott et al. 2002). A summary of protein-protein interactions within the archaeal RNase P holoenzyme is shown in Figure 5.

Recently, the reconstitution of enzymatic activity from RNase P RNA synthesized by in vitro transcription and the homologs of the four known RNase P proteins in Pyrococcus horikoshi has been reported (Kouzuma et al. 2003), and this has been confirmed in M. thermoautotrophicus (Boomershine et al. 2003); these four proteins and the RNA, therefore, are the essential components of the holoenzyme. Based upon the identity of protein subunits that appear to be homologous to those from the eukaryotic nucleus, and the similarity of the protein-protein contacts in the yeast and archaeal RNase P complexes, it seems likely that the structure of the holoenzyme from the Eukarya and Archaea are remarkably similar. This presumption was the basis for the recent successful efforts to reconstitute RNase P function from the human RNA and only these four core proteins (Mann et al. 2003). In light of the overall similarity of the archaeal RNase P RNA structures to those of the Bacteria (Harris et al. 2001), and the similarity of the archaeal RNase P proteins with a functional core to those of the eukaryotic nucleus, it will be interesting to one day compare the three-dimensional architecture of RNase P from the three major domains of life.

\section{Acknowledgments}

We thank David Engelke and Felica Scott-Hauser for assistance with the yeast two-hybrid experiments, useful discussions, and for providing us with data prior to publication. We also thank David Dotson for providing yeast media. This work was supported by NIH grant GM52894 to JWB, and Graduate Assistantships in Areas of National Needs (GAANN) fellowship to TAH, and is dedicated to the memory of Dr. Elizabeth Suzanne Haas (1957-2002).

\section{References}

Andrews, A.J., T.A. Hall and J.W. Brown. 2001. Characterization of RNase P holoenzymes from Methanococcus jannaschii and Methanothermobacter thermoautotrophicus. Biol. Chem. 382: 1171-1177.

Baer, M.F., D. Wesolowski and S. Altman. 1989. Characterization in vitro of the defect in a temperature-sensitive mutant of the protein subunit of RNase P from Escherichia coli. J. Bacteriol. 171: 6862-6866.

Bartel, P., C. Chien, R. Sternglanz and S. Fields. 1993. Elimination of false positives that arise in using the two-hybrid system. Biotechniques 14:920-924.

Boomershine, W.P., C.A. McElroy, H.-Y. Tsai, R.C. Wilson, V. Gopalan and M.P. Foster. 2003. Structure of Mth11/Mth Rpp29, an essential protein subunit of archaeal and eukaryotic RNase P. Proc. Natl. Acad. Sci. 100:15,398-15,403.

Chamberlain, J.R., Y. Lee, W.S. Lane and D.R. Engelke. 1998. Purification and characterization of the nuclear RNase P holoenzyme complex reveals extensive subunit overlap with RNase MRP. Genes Dev. 12:1678-1690.

Chen, J.L. and N.R. Pace. 1997. Identification of the universally conserved core of ribonuclease P RNA. RNA 3:557-560.

Chen, J.L., J.M. Nolan, M.E. Harris and N.R. Pace. 1998. Comparative photocross-linking analysis of the tertiary structures of Escherichia coli and Bacillus subtilis RNase P RNAs. EMBO J. 17: 1515-1525.

Eder, P.S., R. Kekuda, V. Stolc and S. Altman. 1997. Characterization of two scleroderma autoimmune antigens that copurify with human ribonuclease P. Proc. Natl. Acad. Sci. 94:1101-1106.

Fang, X.W., X.J. Yang, K. Littrell, S. Niranjanakumari, P. Thiyagarajan, C.A. Fierke, T.R. Sosnick and T. Pan. 2001. The Bacillus subtilis RNase P holoenzyme contains two RNase P RNA and two RNase P protein subunits. RNA 7:233-241.

Frank, D.N. and N.R. Pace. 1998. Ribonuclease P: unity and diversity in a tRNA processing ribozyme. Annu. Rev. Biochem. 67: 153-180.

Frank, D.N., C. Adamidi, M.A. Ehringer, C. Pitulle and N.R. Pace. 2000. Phylogenetic-comparative analysis of the eukaryal ribonuclease P RNA. RNA 6:1895-1904.

Guerrier-Takada, C., K. Gardiner, T. Marsh, N. Pace and S. Altman. 1983. The RNA moiety of ribonuclease $P$ is the catalytic subunit of the enzyme. Cell 35:849-857.

Guerrier-Takada, C., P.S. Eder, V. Gopalan and S. Altman. 2002. Purification and characterization of Rpp25, an RNA-binding protein subunit of human ribonuclease P. RNA 8:290-295.

Hall, T.A. and J.W. Brown. 2002. Archaeal RNase P has multiple protein subunits homologous to eukaryotic nuclear RNase $\mathrm{P}$ proteins. RNA 8:296-306. 
Harris, J.K., E.S. Haas, D. Williams, D.N. Frank and J.W. Brown. 2001. New insight into RNase P RNA structure from comparative analysis of the archaeal RNA. RNA 7:220-232.

Hollenberg, S.M., R. Sternglanz and H. Weintraub. 1995. Identification of a new family of tissue-specific basic helix-loop-helix proteins with a two-hybrid system. Mol. Cell. Biol. 15:3813-3822.

Houser-Scott, F., S. Xiao, C.E. Millikin, J.M. Zengal, L. Lindahl and D.R. Engelke. 2002. Interactions among the protein and RNA subunits of Saccharomyces cerevisiae nuclear RNase P. Proc. Natl. Acad. Sci. 99:2684-2698.

Jarrous, N. 2002. Human ribonuclease P: subunits, function, and intranuclear localization. RNA 8:1-7.

Jarrous, N. and S. Altman. 2001. Human ribonuclease P. Meth. Enzymol. 342:93-100.

Jarrous, N., P.S. Eder, C. Guerrier-Takada, C. Hoog and S. Altman. 1998. Autoantigenic properties of some protein subunits of catalytically active complexes of human ribonuclease P. RNA 4:407-417.

Jarrous, N., P.S. Eder, D. Wesolowski and S. Altman. 1999. Rpp14 and Rpp29, two protein subunits of human ribonuclease P. RNA 5: 153-157.

Jiang, T. and S. Altman. 2001. Protein-protein interactions with subunits of human nuclear RNase P. Proc. Natl. Acad. Sci. 98: 920-925.

Jiang, T., C. Guerrier-Takada and S. Altman. 2001. Protein-RNA interactions in the subunits of human nuclear RNase P. RNA 7: 937-941.

Kazantsev, A.V., A.A. Krivenko, D.J. Harrington, R.J. Carter, S.R. Holbrook, P.D. Adams and N.R. Pace. 2003. High-resolution structure of RNase P protein from Thermotoga maritima. Proc. Natl. Acad. Sci. 100:7497-7502.

Kirsebom, L.A. and A. Vioque. 1995. RNase P from bacteria. Substrate recognition and function of the protein subunit. Mol. Biol. Rep. 22:99-109.

Koonin, E.V., Y.I. Wolf and L. Aravind. 2001. Prediction of the archaeal exosome and its connections with the proteasome and the translation and transcription machineries by a comparativegenomic approach. Genome Res. 11:240-252.

Kouzuma, Y., M. Mizoguchi, H. Takagi, H. Fukuhara, M. Tsukamoto, T. Numata and M. Kimura. 2003. Reconstitution of archaeal ribonuclease P from RNA and four protein components. Biochem. Biophys. Res. Commun. 306:666-673.

Lee, J.Y. and D.R. Engelke. 1989. Partial characterization of an RNA component that copurifies with Saccharomyces cerevisiae RNase P. Mol. Cell Biol. 9:2536-2543.

Lee, J.Y., C.E. Rohlman, L.A. Moloney and D.R. Engelke. 1991. Characterization of $R P R l$, an essential gene encoding the RNA component of Saccharomyces cerevisiae nuclear RNase P. Mol. Cell Biol. 11:721-730.
Lygerou, Z., H. Pluk, W.J. van Venrooij and B. Seraphin. 1996. hPop1: An autoantigenic protein subunit shared by the human RNase P and RNase MRP ribonucleoproteins. EMBO J. 15: 5936-5948.

Mann, H., Y. Ben-Asouli, A. Schein, S. Moussa and N. Jarrous. 2003. Eukaryotic RNase P: role of RNA and protein subunits of a primordial catalytic ribonucleoprotein in RNA-based catalysis. Mol. Cell 12:925-935.

Massire, C., L. Jaeger and E. Westhof. 1998. Derivation of the threedimensional architecture of bacterial ribonuclease P RNAs from comparative sequence analysis. J. Mol. Biol. 279:773-793.

Pace, N.R. and J.W. Brown. 1995. Evolutionary perspective on the structure and function of ribonuclease $\mathrm{P}$, a ribozyme. J. Bacteriol. 177:1919-1928.

Pannucci, J.A., E.S. Haas, T.A. Hall, J.K. Harris and J.W. Brown. 1999. RNase P RNAs from some Archaea are catalytically active. Proc. Natl. Acad. Sci. 96:7803-7808.

Pitulle, C., M. Garcia-Paris, K.R. Zamudio and N.R. Pace. 1998. Comparative structure analysis of vertebrate ribonuclease P RNA. Nucleic Acids Res. 26:3333-3339.

Schön, A. 1999. Ribonuclease P: the diversity of a ubiquitous RNA processing enzyme. FEMS Microbiol. Rev. 23:391-406.

Soni, R., J.P. Carmichael and J.A. Murray. 1993. Parameters affecting lithium acetate-mediated transformation of Saccharomyces cerevisiae and development of a rapid and simplified procedure. Curr. Genet. 24:455-459.

Spitzfaden, C., N. Nicholson, J.J. Jones, S. Guth, R. Lehr, C.D. Prescott, L.A. Hegg and D.S. Eggleston. 2000. The structure of ribonuclease P protein from Staphylococcus aureus reveals a unique binding site for single-stranded RNA. J. Mol. Biol. 295:105-115.

Stams, T., S. Niranjanakumari, C.A. Fierke and D.W. Christianson. 1998. Ribonuclease P protein structure: evolutionary origins in the translational apparatus. Science 280:752-755.

Thomas, B.C., J. Chamberlain, D.R. Engelke and P. Gegenheimer. 2000. Evidence for an RNA-based catalytic mechanism in eukaryotic nuclear ribonuclease P. RNA 6:554-562.

Thomas, B.C., X. Li and P. Gegenheimer. 2000. Chloroplast ribonuclease $\mathrm{P}$ does not utilize the ribozyme-type pre-tRNA cleavage mechanism. RNA 6:545-553.

Tsai, H.Y., B. Masquida, R. Biswas, E. Westhof and V. Gopalan. 2003. Molecular modeling of the three-dimensional structure of the bacterial RNase P holoenzyme. J. Mol. Biol. 325:661-675.

van Eenennaam, H., D. Lugtenberg, J.H.P. Vogelzangs, W.J. van Venrooij and G.J.M. Pruijn. 2001. hPop5, a protein subunit of the human RNase MRP and RNase P endoribonucleases. J. Biol. Chem. 276:31,635-31,641. 

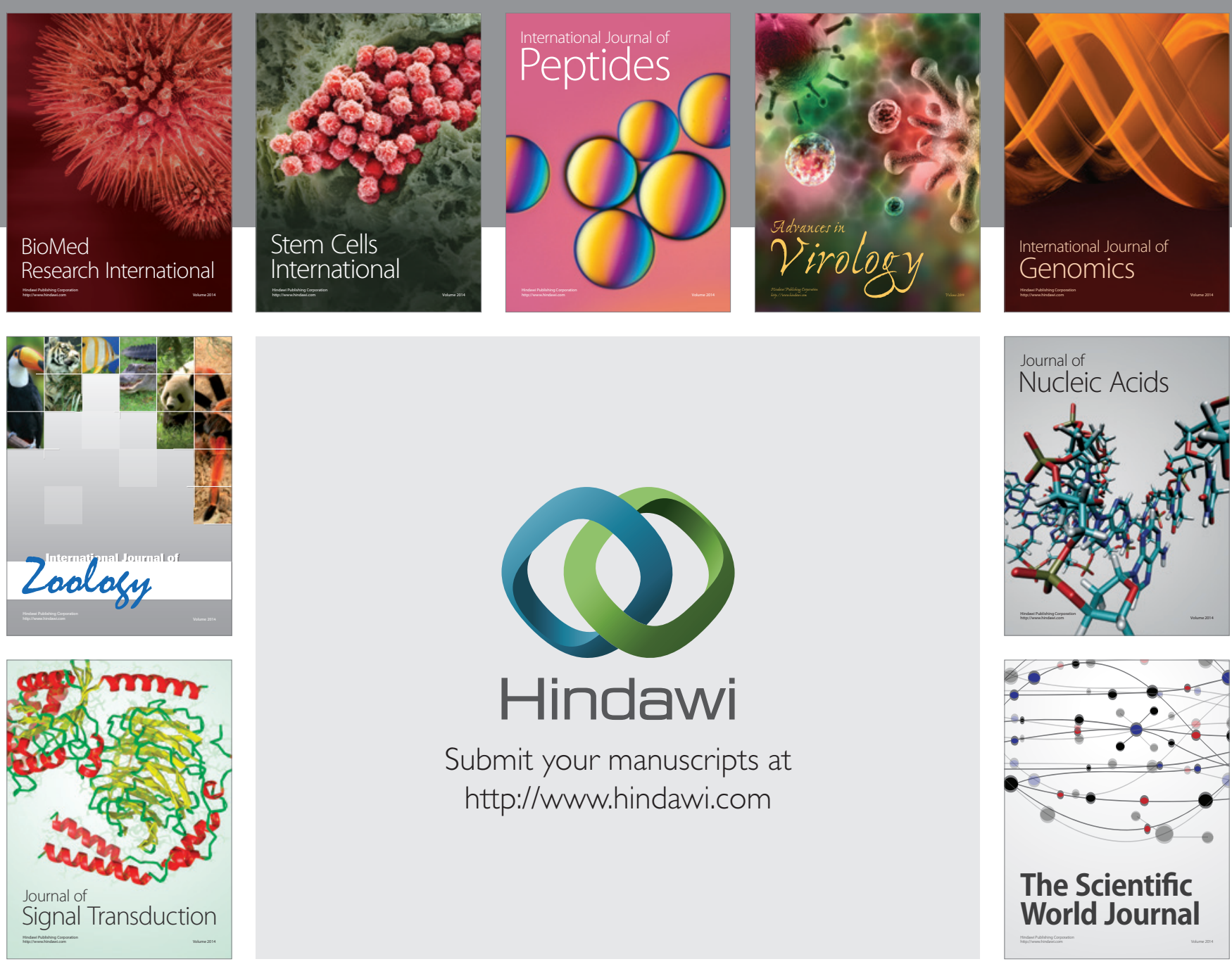

Submit your manuscripts at

http://www.hindawi.com
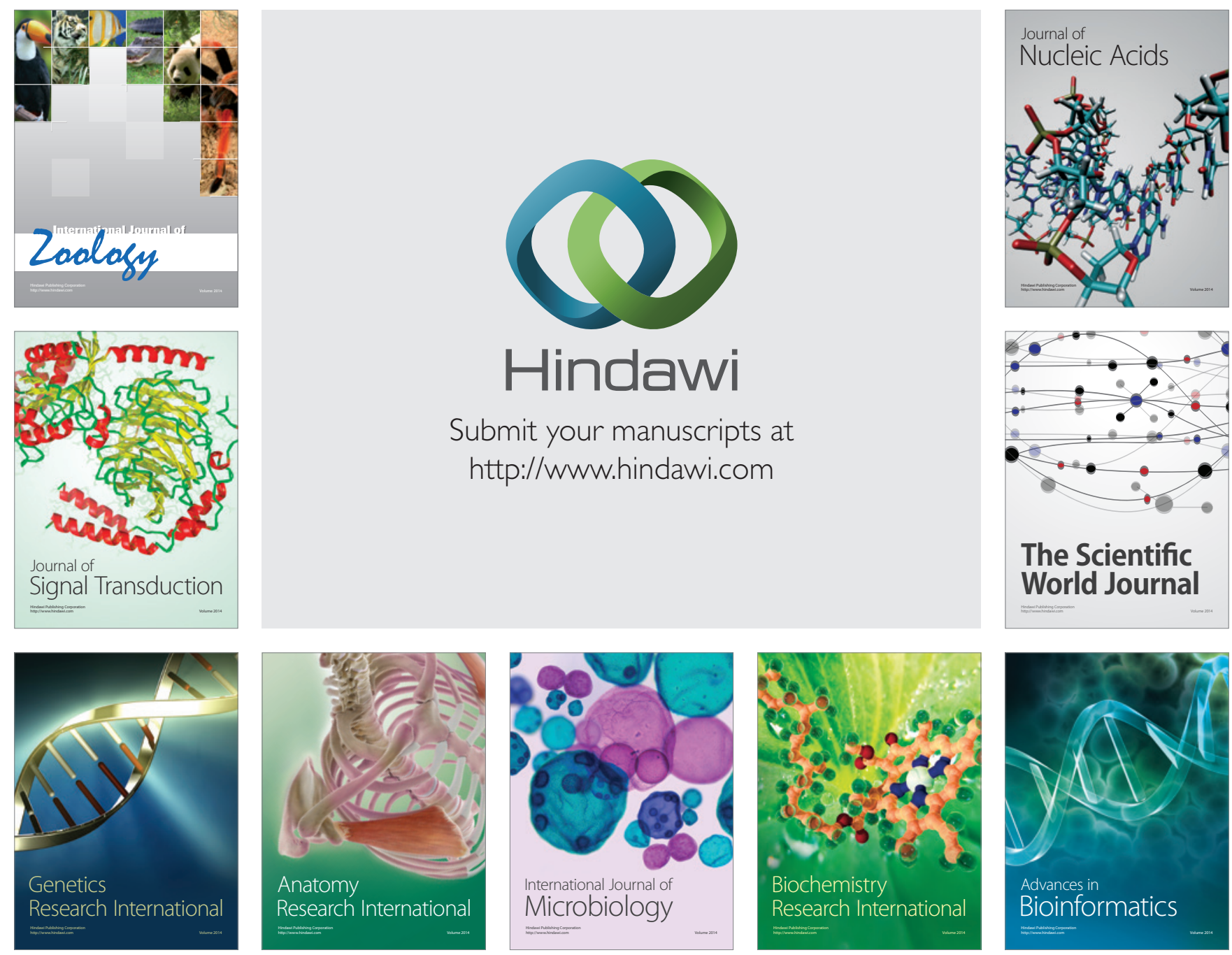

The Scientific World Journal
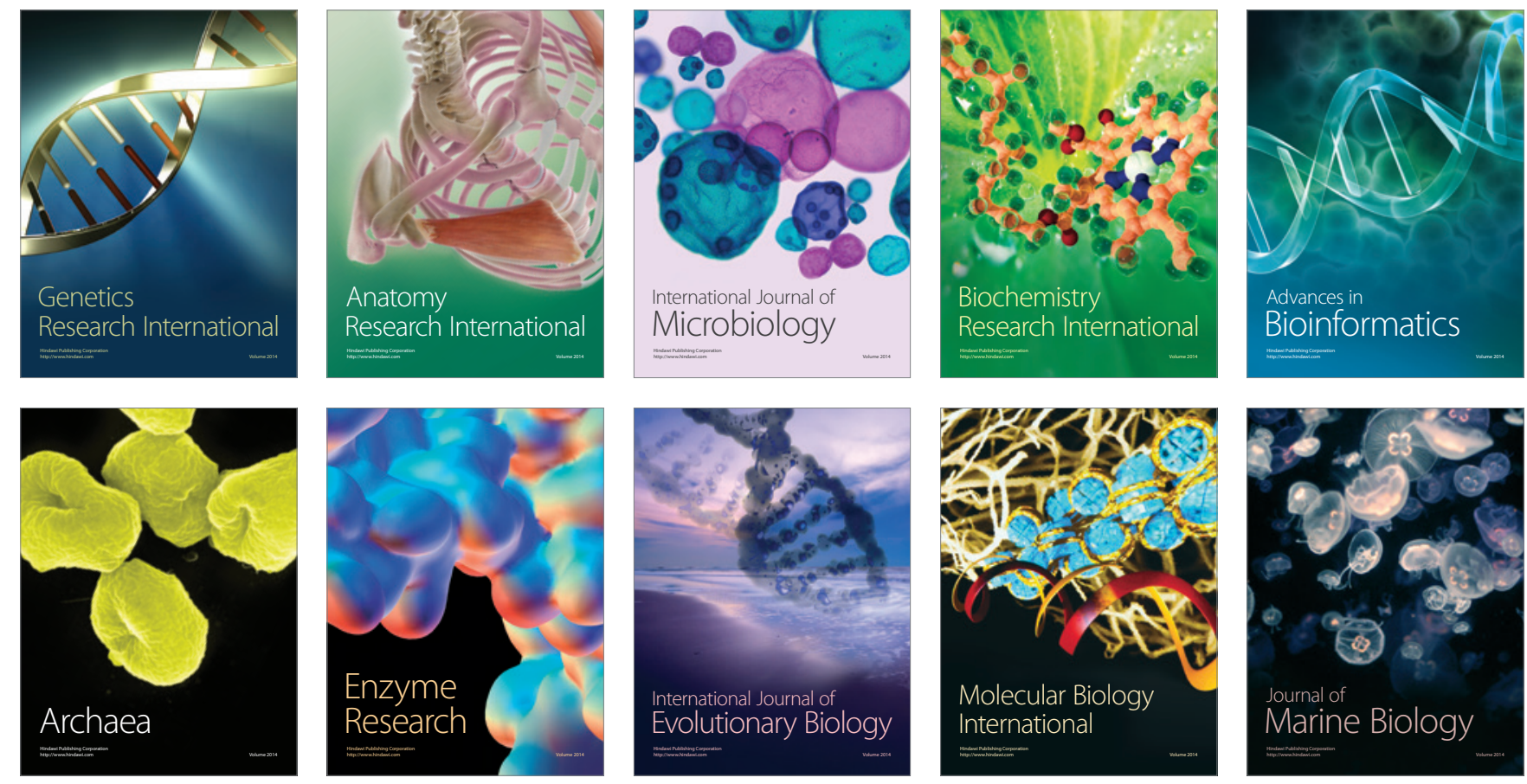